\title{
The Enfranchisement of Women and the Welfare State*
}

\author{
Graziella Bertocchi \\ Universita' di Modena e Reggio Emilia, CEPR, CHILD and IZA
}

May 2008

\footnotetext{
*I would like to thank Tim Callan, Mark Gradstein, Joel Mokyr, Andrew Oswald, Chiara Strozzi, Guido Tabellini, and participants at the LoWER Conference on Gender, the LabSI Conference on Political Economy and Public Choice, the Conference on Institutional and Social Dynamics of Growth and Distribution, the BOMOPA Meetings 2008, and seminars at the Catholic University of Milan and the University of Naples Parthenope, for helpful comments and suggestions. Address for correspondence: Dipartimento di Economia Politica, Università di Modena e Reggio Emilia, Viale Berengario, 51, I-41100 Modena, Italy, phone 39059 2056856, fax 39059 2056947, e-mail graziella.bertocchi@unimore.it,web http://www.economia.unimore.it/Bertocchi_Graziella/.
} 


\begin{abstract}
We offer a rationale for the decision to extend the franchise to women within a politico-economic model where men are richer than women, women display a higher preference for public goods, and women's disenfranchisement carries a societal cost. We first derive the tax rate chosen by the male median voter when women are disenfranchised. Next we show that, as industrialization raises the reward to mental labor relative to physical labor, women's relative wage increases. When the cost of disenfranchisement becomes higher than the cost of the higher tax rate which applies under universal enfranchisement, the male median voter is better off extending the franchise to women. A consequent expansion of the size of government is only to be expected in societies with a relatively high cost of disenfranchisement.

We empirically test the implications of the model over the 1870-1930 period. We proxy the gender wage gap with the level of per capita income and the cost of disenfranchisement with the presence of Catholicism, which is associated with a more traditional view of women's role and thus a lower cost. The gender gap in the preferences for public goods is proxied by the availability of divorce, which implies marital instability and a more vulnerable economic position for women. Consistently with the model's predictions, women suffrage is affected positively by per capita income and negatively by the presence of Catholicism and the availability of divorce, while women suffrage increases the size of government only in non-Catholic countries.
\end{abstract}

JEL Classification Numbers: P16, J16, N40, H50, 011.

Key Words: women suffrage, inequality, public goods, welfare state, culture, family, divorce. 


\begin{abstract}
“... the exclusion of women (...) from any share in the representation (...) violates one of the oldest of our constitutional maxims (...) that taxation and representation should be co-extensive."
\end{abstract}

John Stuart Mill, House of Commons, 20 May 1867

\title{
1 Introduction
}

Despite the fact that women represent at least half of the world population, in the large and growing literature on suffrage extension and its economic causes and effects little attention has been devoted to the analysis of women's enfranchisement. Historically, in the vast majority of cases, women were the last to be granted the right to vote, thus coming after poor men. This consideration casts doubts on the relevance, when applied to women suffrage, of the often purely economic arguments developed in the literature on franchise extension.

In this paper, we derive and test a political economy model which offers a rationale for the decision to extend the franchise to women. The basic idea behind our theory is that the franchise is always extended by a group with power to a group without power when an event, or a sequence of events, interferes with its decision making process. Our goal is to understand which factors are involved when the first group is represented by men, and the second by women.

While the focus of the paper is on that unique transitional period that runs from the last few decades of the nineteenth century until the 1930s, when the franchise is extended to women in those countries that are now modern industrial democracies, the implications of our results can also be usefully applied to a comparative analysis of women's rights across countries with different levels of development. The World Economic Forum Global Gender Gap Report (2007) shows that women' political empowerment is far from complete even in the most advanced countries, with top-scoring Sweden at $52.5 \%$, and that there is still considerable cross-country variation, with Yemen at the lowest rank with a score of $0.8 \%$.

The main assumptions on which our model rests are the following.

First, men are richer than women, since men and women are endowed with equal amounts of mental labor, while men have a larger endowment of physical labor than women. Since the development process affects the relative reward of mental and physical labor, the resulting wage gap evolves over time reflecting well-known stylized facts. 
Our second assumption is that women display a higher preference for public goods, which may reflect different degrees of risk aversion and different perceptions of the role of government as a potential insurer. Gender differences in the taste for public goods have been documented in several contexts. Family structure can be an explanations for this pattern, so that institutions affecting the stability of family structure, such as divorce, can be related to women's preferences.

Our third assumption is that there is a cost for society associated with women's disenfranchisement. This cost is determined by a country's culture, and in particular its family culture, i.e., the perceptions of women's role within the family and in society at large, including women's economic, social, and political roles. Religion is a primary explanation of the observed cross-country differences in such attitudes, with Catholicism being associated with a more traditional women's role and thus a lower cost of disenfranchisement.

We introduce the above three assumptions within a dynamic politico-economic model populated by overlapping generations of constant size and with stationary endowments. The technology combines capital with the two kinds of labor endowments, physical and mental labor, in such a way that the richer in capital is an economy, the more highly rewarded is mental labor relative to physical. Finally, there is a government that levies a proportional income tax in order to finance a public good.

In the resulting framework, we compare the preferred tax rate of the median voter under full male suffrage - and full female disenfranchisement - with the preferred tax rate under universal suffrage. We show that, as the economy industrializes and the reward to mental labor increases relative to physical labor, the relative wage of women increases, until the time when, for the male median voter, the cost of women's disenfranchisement is higher than the cost of accepting the median voter's choice under universal suffrage. The male median voter is therefore better off extending the franchise to women, since economic development and the consequent reduction of the gender wage gap make the women's preferred tax rate closer to that of the men's, thus increasing the relative cost of disenfranchisement, until it makes no sense for the men to keep women from voting. We also explore the implications for the size of government, and show that its expansion following women's enfranchisement is to be expected only in societies where the cost of disenfranchisement is high relative to the gender-related gaps in wages and public good preferences, i.e., in countries with a progressive culture.

The second part of the paper tests the implications of the model for a sample of 22 countries over the 1870-1930 period. The model's main predictions are that the decision to enfranchise women is 
affected negatively by the gender gaps in wages and in the preferences for public goods, positively by the cost of disenfranchisement. We proxy the gender wage gap inversely with the level of income per capita. We capture the cost of disenfranchisement with a measure of society's culture given by religion, where the presence of Catholicism is associated with a more conservative perception of the gender role and thus with a smaller cost. The proxy we employ for the gender gap in the preferences for public goods is the availability of divorce, which implies marital instability and a more vulnerable social and economic position for women, and therefore a higher female preference for government and redistribution. We show that, consistently with the model's predictions, women suffrage is affected positively by the level of per capita income and negatively by the presence of Catholicism and the availability of divorce, even after controlling for the general level of democracy. Moreover, we show that the size of government tends to be positively affected by women suffrage, as uncovered by previous studies, but also that the negative impact of the interaction between women suffrage and the proportion of Catholics indicates that the impact of women suffrage is lowest in conservative, Catholic societies where disenfranchisement costs are small, since under small costs the franchise is extended only when the gender gaps are small, implying a small increase in the resulting tax rate.

The paper is organized as follows. Section 2 introduces the related literature. Section 3 reviews the historical evidence on the enfranchisement of women and the evolution of divorce legislation in the relevant time period. Section 4 presents the basic model. Section 5 contains the analysis of the model. Section 6 explores extensions of the basic model. Section 7 empirically tests the implications of the model. Section 8 summarizes our findings and indicates directions for related future research.

\section{Related literature}

While the issue of franchise extension has recently received considerable attention within the literature on institutions, with contributions by Acemoglu and Robinson (2000), Bertocchi and Spagat (2001), Justman and Gradstein (1999), Lizzeri and Persico (2004), and Llavador and Oxoby (2005), few papers have so far specifically focused on the determinants of the extension of the franchise to women. While our goal is to provide a theoretical and empirical investigation of the determinants of female empowerment - as captured by the voting franchise - at the societal level, Doepke and Tertilt (2007) model the impact of education and human capital on the relative bargaining posi- 
tion of men and women within the family, and Geddes and Lueck (2002) empirically evaluate the determinants of women's property rights in the US in the 1850-1920 period.

Several papers, on the other hand, investigate the related question of the impact of women's enfranchisement on the size and composition of government. Lindert (1994) presents a broader empirical investigation on the determinants of the rise in social spending the 1880-1930 period. His sample therefore includes the unique transitional period between the males-only franchise and the extension of the franchise to women, for which he finds a positive impact on the size of government. Lott and Kenny (1999) investigate the same issue for the United States in the 1870-1940 period and again find a positive effect. They also find evidence that the gender gap at least in part arises from women's fear that they can be left to raise children on their own, and conclude that family breakdown and increasing divorce rates may be a channel through which women's preferences may affect government size. Aidt et al. (2006) focus on the impact of democracy on government spending in 1830-1938 Europe and confirm that female suffrage has a positive impact, through spending on collective goods such health, education and welfare. They also stress the differential impact of franchise extension to men and women, where the former had contributed to the general growth in government mainly through an expansion of spending on security and long-term public services. Aidt and Dallal (2008) present further evidence on a positive and sizeable long-run impact of women suffrage on spending for six Western European countries for the period 1869-1960. The post-war experience is often focused on the case of Switzerland, which granted women voting rights only in 1971, thus providing ground for a unique natural experiment. Abrams and Settle (1999) show that women suffrage raised the overall size of the Swiss government, and that this occurred through welfare spending, but not government consumption. At the cantonal level, Funk and Gathmann (2005) find larger gender differences regarding the scope, rather than the size, of government, with a negative overall impact and differential effects across different kinds of expenditures. For instance, women oppose some types of expenditures such as welfare, education, security, while support environment and culture. Also at the cantonal level, Krogstrup and Walti (2006) find that including women in the electorate increases average per capita budget balances. ${ }^{1}$

The above literature on women suffrage and government size is closely related to a parallel line of research which has studied the discrepancy between men's and women's political preferences.

\footnotetext{
${ }^{1}$ The relevance of gender for fiscal policy is also explored by Alesina and Ichino (2007), who review the theory of optimal taxation in light of the fact that labor supply elasticity is higher for women than for men, and show that income tax rates should be lower for women than for men.
} 
The common denominator between these two branches of the literature is the idea is that women care more about social issues and that they tend to be poorer than men. The reasons for these differences can be found in societal modernization, which brings marital instability and an evolution of traditional sex roles. In particular, the diffusion of divorce and the evolution of the relevant legislation are viewed as possible reasons why, at least in the past few decades, women prefer higher public expenditures than men, and therefore vote for those parties, typically of the Left, that favor heavier public intervention. The argument can be related to that in Lott and Kenny (1999), previously mentioned with regard to the impact of women's choice on the size of government in 1870-1940 US case. In particular, Edlund and Pande (2001) study the evolution of the political gender gap during the last three decades in the United States, where women have increasingly favored the Democratic party, and trace these developments to the decline in marriage. In particular, they show a strong positive correlation between state divorce prevalence and the political gender gap, with higher divorce prevalence reducing support for the Democrats among men but not women. ${ }^{2}$ Washington (2006) tests the hypothesis that parenting daughters increases support for women's issues and shows that the propensity to vote liberally on reproductive rights is significantly increasing in a US Congress member's proportion of daughters. Oswald and Powdthavee (2006) model the idea that daughters make people more left-wing and provide supporting evidence for Britain. How the composition of public spending can be affected by gender-based differences in tastes for public goods is the question addressed by Chattopadhyay and Duflo (2004), who find that women's political influence in village councils in India matters substantially for the types of public goods provided. ${ }^{3}$

Since culture, as captured by religion, plays a crucial role in our theoretical and empirical analysis, we also contribute to recent research on the economic impact of culture - including papers by Fernandez and Fogli (2007), Giuliano (2007), Guiso et al. (2006), and Tabellini (2005) - and particularly religion, since religion seems to be a particularly important cultural trait as far as family attitudes and the perception of women's role are concerned. Contributions include Bisin and Verdier (2000), Guiso et al. (2003), Botticini and Eckstein (2005), and Algan and Cahuc (2006).

\footnotetext{
${ }^{2}$ Friedberg (1998) also explores the impact of unilateral divorce laws on divorce rates, while Stevenson and Wolfers (2007) study the influence of divorce reforms on family formation decisions.

${ }^{3}$ Cavalcanti and Tavares (2006) explore another complementary reason why women may prefer larger government, by assuming that government spending decreases the cost of performing household chores. Experimental evidence from standard public goods games, collected by Cipriani et al. (2007), also suggests that boys are less cooperative than girls.
} 
In particular, Guiso et al. (2003) use the World Value Survey to identify the relationship between intensity of religious beliefs and attitudes toward women and find that religious people tend to be less favorable with respect to working women. However, they do not focus on the relative impact of different religious denominations. Algan and Cahuc (2006) provide international micro-evidence to show that the male breadwinner values are highly positively correlated with the fact to be a Catholic or a Muslim.

Finally, this paper also connects to the literature which has studied the economic position of women, linking it to the stages of the development process. The existence of a discrepancy between men's and women's earnings has been well-documented at least since biblical times. Their gradual convergence since the second part of the nineteenth century, however, has also been substantial. Goldin (1990) shows that full-time earnings of American women rose from 46 to 67 percent of men's earnings over the 1890-1988 period, and links these findings to the impact of industrialization and the increased importance of non-manual skills. Galor and Weil (1996) study the determinants of women's relative wage in a model where industrialization promotes the role of mental labor relative to an agrarian economy where physical labor is more rewarded. The gender wage gap can therefore be directly related to the agricultural share of labor, and tends to decrease as the role of agriculture declines. Owen and You (2005) find that the process of development has a positive impact on attitudes towards women and on the quality and quantity of women's human capital. The transition from agriculture to manufacturing influences not only the gender wage gap, but more generally the workings of the family, including parenting decisions and intergenerational links, as established by Galor and Moav (2002) and Bertocchi (2006), respectively.

\section{Historical evidence}

In the first subsection below we present the main historical facts related to the extension of the franchise to women. Among the determinants of women suffrage that our model and the subsequent empirical analysis highlight, a prominent role is played by economic considerations captured by the gender wage gap. For the relevant stylized facts of its evolution we refer to Goldin (1990). ${ }^{4}$ The historical role of the Roman Catholic church in shaping family culture, which also plays a crucial role in our context, is relatively well-known (see Algan and Cahuc, 2006, for an exhaustive discussion), while less is known in the economic literature about the history of divorce, which we link to women's

\footnotetext{
${ }^{4}$ The decision to enfranchise women is also generally preceded by a gradual rise of women's labor force participation (see Costa, 2000), which reinforces the impact of the reduction of the gender wage gap.
} 
preferences for public goods. Therefore, in the second subsection, we supply specific evidence on the evolution of divorce legislation during the relevant time period.

Table 1 summarizes information on the timing of the introduction of women suffrage and divorce in the 22 countries of our sample. The discussion below is, however, more general, and thus touches on a larger set of countries.

\subsection{The enfranchisement of women}

In this section we briefly discuss the historical evidence related to the extension of the franchise to women. The period that goes from the end of the nineteenth century until the 1920s witnessed a first wave of extensions of the franchise to women, despite marked cross-country differentiation even within Europe. Opposition to women's enfranchisement came from a view of women as subordinate to men and unable to form independent political judgement, and from the idea - strongly supported by the clergy, and in particular by the Roman Catholic church - that the only place for a woman was to be the home. Even Left-wing parties were often against women enfranchisement, out of fear that women might make conservative political choices.

In 1893 New Zealand became the first country to grant women the right to vote in national elections. Australia followed in 1902. In the United States an organized movement on behalf of woman suffrage first emerged in 1848. By 1910 women had the right to vote in Wyoming, Utah, Idaho, Colorado, and Washington, but it is only following the active participation of women to World War I that in 1919 Congress passed by a narrow margin a woman suffrage constitutional amendment which was ratified by the states in 1920. Canada adopted national legislation on this issue in 1917.

Within Europe, the first country to extend the franchise to women in national elections was Finland in 1907. The rest of Scandinavia quickly followed suit, with Norway and Denmark also allowing women to vote before World War I, while Sweden waited until 1919. British women's struggle to achieve the right to vote has a long history culminating with the "suffragettes" movement, which intensified its action around 1905. Nevertheless, as for the United States, it is only after World War I that women succeeded in achieving the vote, which in 1918 was granted to women over age 30. In 1928 the franchise finally became universal. Germany's Weimar Republic included women in the electorate in 1918. In the same year Austria and most Eastern European countries did so, while Belgium the Netherlands joined in 1919. Turning the attention to Southern Europe, Spain and Portugal enfranchised women in the 1930s, while a subsequent wave of legislation had 
to wait until after World War II, when France, Italy and Greece granted women the franchise in 1944, 1945 and 1952, respectively. A unique exception in Europe is represented by Switzerland, where women were granted the vote only in 1971.

Outside Europe, among the late-comers we find Japan, China and India, that granted women the franchise between 1945 and 1950. In Latin America there was a first wave of legislation in the 1930s (involving Ecuador, Chile, Brazil), while Argentina and Mexico only joined after World War II. Similarly, South Africa granted the franchise to white women in 1930, while most other African countries enfranchised women after the war and ratified the universal franchise in the post-decolonization constitutions. Currently, most countries in the world grant women the voting franchise, with a few exceptions, notably the countries of the Persian Gulf. However, Kuwait recently introduced the women's franchise in 2005 .

To be noticed is that women suffrage only represents a first step in the achievement of equal political rights, and generally comes before women are allowed to run for office. To be also noticed is that in several cases men suffrage became universal before women suffrage, and that there are very few examples of women being enfranchised before men of the same social class or race. Fleck (1993) provides a synopsis for the developments just described. Further details are available for example in DuBois (1998) and Flexner and Fitzpatrick (1996).

\subsection{The introduction of divorce legislation}

The standard reference for the history of divorce is Phillips (1988). He provides a broad analysis of the way divorce laws were transformed during the nineteenth century and the decades immediately following it.

In Europe, before the nineteenth century a sizeable number of countries with a Protestant population (the Netherlands, Sweden, Norway, Denmark, Finland and Switzerland) had provisions allowing divorce which dated back at least to the Reformation, while divorce was generally unavailable in Catholic countries. Religious authorities in Orthodox countries such as Greece and Russia allowed divorce, although they discouraged it. In 1783 divorce was extended to the non-Catholic populations of Austria and the Austrian territories, but Austria had to wait until the Nazi divorce law of 1938 for an extension of the legislation to Austrian Catholics. After the Napoleonic conquests, divorce - which had been adopted in France in 1792 with the Revolution, through a very liberal legislation - was introduced in the countries of the French Empire. With the Restoration, however, France abolished divorce in 1816, only to reintroduce it in 1884. In 1830 Belgium became 
independent but, despite the fact that it previously allowed divorce only to the non-Catholic population, it legalized divorce for all citizens using the Napoleonic Code as a model. In 1857 England's first divorce law was passed, after nearly three centuries of pressure. Previously, divorce in England had only been possible through an Act of Parliament. In Italy opposition by the Roman Catholic church was strong, so that Italy did not recognized divorce in its 1865 new civil code after unification. In 1875 Germany extended divorce laws beyond the Protestant states of northern Germany to Catholic states of the South. In Portugal and Spain divorce was introduced relatively early (1910 and 1932, respectively), only to be revoked in 1940 and 1939, and finally reintroduced in 1977 and 1981.

Moving outside Europe, the 1857 British divorce law had global implications since the British legislation became the model throughout the British Empire. Australia and New Zealand soon adopted similar provisions. However, divorce was not recognized in Canada at the federal level until 1968, while before that time the only way to get divorced was to apply to the Canadian Senate. In the United States divorce legislation fell within the jurisdiction of the states. Many of the states of the North-East introduced divorce legislation soon after independence, in the 1780s and 1790s. In the South the developments were slower, but by 1860 all states except South Carolina had passed divorce laws. The Western states rapidly installed liberal divorce laws during the first decades of the nineteenth century. Japan had divorce provisions at least since 1868. In Argentina and Brazil divorce laws were passed in 1954 and 1975, respectively.

Post-war developments in Europe, beside the afore-mentioned cases of Spain and Portugal, include the cases of Italy and Ireland. Italy's introduction of divorce legislation in 1970 was followed by a fierce but unsuccessful struggle, supported by the Roman Catholic church, to abolish it. In the Republic of Ireland divorce was prohibited by the 1937 Constitution. In 1986, the electorate rejected the possibility of allowing divorce in a referendum but, after a second referendum in 1995 the prohibition of divorce was repealed and, despite church opposition, divorce was finally approved in 1996.

Moral and religious issues were raised during the decades preceding World War I within the discussion that surrounded the legislative activity. A long-debated question was whether divorce was harmful or beneficial to women. Proponents of divorce argued that women could only benefit from a legislation that protected them from oppressive marriages, while opponents feared that divorce would make women more vulnerable, both economically and socially. Even the women's rights movement was divided on the matter of divorce liberalization, and some feminists perceived 
divorce as a threat for women, rather than a way to liberate themselves.

Overall, by the outbreak of World War I divorce had spread geographically even in predominantly Catholic countries. At the same time, divorce had also become cheaper, faster and more easily accessible, by becoming available from regular courts (judicial divorce), rather than from legislatures (legislative divorce). Moreover, there was a general liberalization with an expansion of the grounds for divorce. The net effect of these changes, combined with more general social and economic developments, was a rapid increase in the number of divorces. The divorce rate (per 1, 000 population) increased in the United States from 0.2 in 1860 to 0.9 in 1910. In the same year, the highest figures elsewhere were represented by Switzerland (0.41) and France (0.36), while most other countries, including Australia and New Zealand, had rates below 0.2.

\section{The basic model}

\subsection{Endowments}

We consider an overlapping generations model where $N$ individuals live for two periods. There is no population growth. In the first period of their life, individuals work and receive a wage income, which is entirely devoted to financing second-period consumption and is therefore saved and invested in the capital market. In their second period, acting as capital owners, individuals receive the return to their savings and consume it entirely, after paying a proportional tax which is used by the government to finance a public good.

Individuals come in two kinds: men and women. Each group has equal size. Men and women differ in two dimensions. First, they differ in their endowments, since they are endowed with different proportions of two kinds of labor input. Following Galor and Weil (1996), we assume that men and women have equal endowments of mental input, but that men have more physical strength than women. To simplify, we simply assume that women have no physical strength.

Beside gender heterogeneity, there is also individual heterogeneity. In particular, each man receives an identical number of units of physical labor, which we normalize at 1 , such that $\ell^{p i}=1$, while endowments of mental labor $\ell^{p i}$ are differentiated across individuals, for $i=1,2, \ldots, N$. Moreover, the distribution of mental labor is assumed to be skewed to the right, i.e., the median mental labor endowment is smaller than the mean $\ell^{m}$. The distribution of mental labor is the same for men and women. It follows that the total supply of physical labor at each $t$ is $L^{p}=\frac{N}{2}$, while the total supply of mental labor is $L^{m}=N \ell^{m}$. 
Men and women also differ in their preferences, as discussed below.

\subsection{Technology}

There are three factors of production: physical capital, $K$, physical labor, $L^{p}$, and mental labor $L^{m}$. Physical labor is the kind of labor in which men have superior abilities to women, i.e., work requiring strength. Mental labor is labor in which men and women have equal abilities. Again following Galor and Weil (1996), at each time $t$ the three factors enter in the production function as follows:

$$
Y_{t}=a\left[\alpha K_{t}^{\rho}+(1-\alpha)\left(L^{m}\right)^{\rho}\right]^{\frac{1}{\rho}}+b L^{p}
$$

where $Y_{t}$ is aggregate output, $a, b>0,0<\alpha<1$, and $-\infty<\sigma<1$. This functional form assumes that physical capital and mental labor exhibit complementarity in production, whereas physical labor is neither a complement nor a substitute for either. This formulation implies that, the richer in physical capital is an economy, the more highly rewarded is mental labor relative to physical labor.

All factors of production are assumed to earn their marginal products as determined by profit maximization under perfect competition. Given the structure of the production technology, the return to a unit of physical labor at time $t, \omega_{t}^{p}$, and the return to mental labor at time $t, \omega_{t}^{m}$, are

$$
\begin{gathered}
\omega_{t}^{p}=b \\
\omega_{t}^{m}=a(1-\alpha)\left(L^{m}\right)^{\rho-1}\left[\alpha K_{t}^{\rho}+(1-\alpha)\left(L^{m}\right)^{\rho}\right]^{\frac{1-\rho}{\rho}}
\end{gathered}
$$

Men earn a wage $w_{t}^{i M}=\omega_{t}^{p}+\omega_{t}^{m} \ell^{p i}$, while women earn a wage $w_{t}^{i F}=\omega_{t}^{m} \ell^{p i}$. Increases in the amount of physical capital, holding mental labor constant, raise the return to mental labor thus reducing the average wage gap between men and women, $w_{t}^{M}-w_{t}^{F}$.

\subsection{Preferences}

Men and women also differ in their preferences, since women display a more pronounced preference for the public good $g_{t}$ which the government provides at each $t$. This difference can be explained by the different role of men and women in society and within the family, with women finding themselves 
in a more vulnerable social and economic position. Following Bolton and Roland (1996), the utility function is

$$
u_{t}^{i j}=c_{t}^{i j}+\gamma^{j} g_{t}
$$

where $c_{t}^{i j}$ is private consumption at time $t$ for an individual born at time $t-1$, for $i=1,2, \ldots, N$ and $j=M, F$, and $\gamma^{j}$, for $j=M, F$, is a parameter which captures gender differences in the preferences for the public good, such that $\gamma^{F}>\gamma^{M}=1$, where the male value of the parameter is normalized to 1 for convenience. The gender-related gap in preferences is therefore defined as $\gamma^{F}-1$.

The individual budget constraint at time $t$ for an individual born at $t-1$ is given by

$$
c_{t}^{i j} \leq\left(1-\tau_{t}\right) y_{t}^{i j}
$$

where $y_{t}^{i j}$ is individual income, with $y_{t}^{i j}=w_{t-1}^{i j} r_{t}$, for $j=M, F, r_{t}$ is the return to capital, and $\tau_{t}$ is a proportional tax rate imposed on individual income.

\subsection{Government}

Tax revenues are used by the government to finance the public good according to the following balanced budget constraint:

$$
g_{t}=\tau_{t} y_{t}-\frac{\tau_{t}^{2}}{2} y_{t}
$$

where $y_{t}$ is mean income at $t$ and the second term captures tax collection costs.

The tax rate is set through a political choice under majority voting, as in Meltzer and Richard (1981). Each enfranchised individual casts a vote at each period on the contemporaneous level of the tax, $\tau_{t}$, such that $0<\tau_{t}<1$. The level of the tax chosen by the median voter varies with the evolution of wage inequality and with the degree of enfranchisement.

We can derive the indirect utility function as

$$
v_{t}^{i j}=\left(1-\tau_{t}\right) y_{t}^{i j}+\gamma^{j}\left(\tau_{t}-\frac{\tau_{t}^{2}}{2}\right) y_{t}
$$

which implies the following expression for an individual's preferred tax rate:

$$
\tau_{t}^{i j}=1-\frac{y_{t}^{i j} / \gamma^{j}}{y_{t}}
$$


To be noticed is that under our assumptions on preferences, even though we allow for two dimensions of heterogeneity - income and gender - our voting problem remains one-dimensional since we can reduce all forms of heterogeneity to a one-dimensional variable $\hat{y}_{t}^{i j}=y_{t}^{i j} / \gamma^{j}$, which Bolton and Roland (1996) label "hedonic income". Since indirect utility is single-peaked with respect to the tax rate, we can apply the median voter theorem and establish that, under universal suffrage, the equilibrium tax rate is the preferred tax rate of the median voter, $\tau_{t}^{*}$, according to

$$
\tau_{t}^{*}=1-\frac{y_{t}^{*} / \gamma^{*}}{y_{t}}
$$

where $y_{t}^{*}$ is median income and $\gamma^{*}$ is the median value of the preferences parameter. The latter is equal to the mean value $\gamma$, where $\gamma=\frac{1}{2}+\frac{1}{2} \gamma^{F}$, with $\gamma^{M}<\gamma<\gamma^{F}$.

\subsection{Dynamic political-economic equilibrium under universal franchise}

Definition 1 A universal-franchise political-economic equilibrium is a sequence $\left\{K_{t}, \tau_{t}^{*}\right\}_{t=0}^{\infty}$ such that at each $t$ utility and profits are maximized, the capital market clears, and the tax rate is optimally set by the median voter, starting from a given initial value of $K_{0}>0$.

The evolution of capital can be tracked by

$$
K_{t}=N w_{t-1}=f\left(K_{t-1}\right)
$$

where $w_{t-1}$ is the average wage at $t-1$ and the function $f$ depends on the technology's parameters $a, b, \alpha$, and $\rho$.

Along the equilibrium path, as physical capital accumulates, women's relative wage increases, thus reducing gender inequality.

Moreover, the redistribution scheme embedded in the way the public good is financed induces convergence of individual incomes. In the long run, the dynamical system evolves towards a steady state which is associated with constant values of $c^{i j}, K, Y$, and $\tau^{*}$.

\section{The enfranchisement of women}

To understand the reasons why the franchise was extended to women at some historical point, we now assume that the voting problem we described in the previous section is constrained by the assumption that men alone are allowed to vote, while all women are disenfranchised. Moreover, we assume that society bears a cost for women's disenfranchisement. This cost can be related to a 
country's culture, and in particular its family culture, i.e., the perceptions of women's role within the family and in society at large, including their economic, social, and political roles. When the cost of women's disenfranchisement is considered, the individual budget constraint is modified as follows:

$$
c_{t}^{i j} \leq\left(1-\tau_{t}\right) y_{t}^{i j}-\delta
$$

To be noticed that the cost $\delta$ could alternatively enter directly in the utility function, without affecting subsequent results. While we model $\delta$ as a fixed cost, our results below hold as long as the cost is increasing over time, or even if it is decreasing but not too fast relative to the other variables we consider. In particular, by endogeneizing the cost of disenfranchisement as a decreasing function of, once again, the gender wage gap, we would obtain a cost which is increasing over time, with a consequent acceleration of women's enfranchisement (see Section 6.1). An increasing cost would be consistent with the historical evidence regarding the gradual strengthening of the movement for women's suffrage. The expression for the indirect utility function of a male individual is now given by

$$
v_{t}^{i M}=\left(1-\tau_{t}\right) y_{t}^{i M}-\delta+\left(\tau_{t}-\frac{\tau_{t}^{2}}{2}\right) y_{t}
$$

Under universal male franchise,${ }^{5}$ the equilibrium tax rate is set by the male median voter as

$$
\tau_{t}^{* M}=1-\frac{y_{t}^{* M}}{y_{t}}
$$

where $y_{t}^{* M}$ is the income level of the male median voter. Since we assumed that $\gamma^{M}=1$, it follows that $\hat{y}_{t}^{i M}=y_{t}^{i M}$, i.e., for a man, there is no distinction between income and hedonic income. Clearly, $\tau_{t}^{* M}$ is smaller than $\tau_{t}^{*}$, the rate set under universal franchise and derived in (9), since the median hedonic income level is now higher, both because of the smaller male preferences parameter and because of the higher median male income. As a consequence, the indirect utility of the male median voter would be reduced if the higher tax rate $\tau_{t}^{*}$, applying in the case of universal franchise, were applied. On the other hand, women's disenfranchisement bears a cost which must be weighted against these considerations. It follows that the male median voter is better off keeping women out of the electoral process if and only if

$$
\left(1-\tau_{t}^{* M}\right) y_{t}^{* M}-\delta+\left[\tau_{t}^{* M}-\frac{\left(\tau_{t}^{* M}\right)^{2}}{2}\right] y_{t} \geq\left(1-\tau_{t}^{*}\right) y_{t}^{* M}+\left[\tau_{t}^{*}-\frac{\left(\tau_{t}^{*}\right)^{2}}{2}\right] y_{t}
$$

\footnotetext{
${ }^{5}$ Consistently with most historical evidence, we assume that the issue of women enfranchisement is posed only after universal franchise is reached for men.
} 
Over time, as the economy industrializes and the reward to mental labor increases relative to physical labor, the relative wage of women increases, thus reducing the gender wage gap and inducing a reduction in the implied $\tau_{t}^{*}$. At some $t$, for the male median voter, the cost of women's disenfranchisement becomes higher than the cost of accepting the higher tax rate which would be chosen by the median voter under universal enfranchisement. It follows that condition (14) is no longer satisfied, so that the male median voter is better off extending the franchise to women.

In practice, the driving force of enfranchisement is the fact that economic development and the consequent reduction of the gender wage gap make the women's preferred tax rate closer to that of the men's. Since the men face a cost of disenfranchisement, as the threat of a women-imposed higher tax fades out, it makes less and less sense for the men to keep women from voting.

In more detail, three factors are involved in the determination of the timing of this decision. First, the larger is the cost of disenfranchisement, and more progressive is society's view of women's role, the sooner the franchise is extended to women. Second, the smaller is the men-women discrepancy in the preferences for the public good, the sooner the enfranchisement. Finally, the franchise is extended sooner in societies where physical labor is less rewarded relative to mental labor, i.e., where capital accumulation and industrialization have reached a more advanced stage. Thus, even assuming, as we do so far, that preferences and cultural factors are time invariant, the model establishes a relationship between the level of economic development and women's political status.

Our main results are summarized in the following proposition.

Proposition 1 (i) A male median voter extends the franchise to women when (14) is no longer satisfied, i.e., when the cost of a suboptimal tax rate outweights the cost of disenfranchisement.

(ii) The franchise is extended to women sooner, the lower is the gender wage gap, $w_{t}^{M}-w_{t}^{F}$; the lower is the gender gap in the preferences for public goods, $\gamma^{F}-1$; and the larger is the cost of disenfranchisement, $\delta$.

To conclude, it should be noticed that, while the model assumes universal male suffrage, the presence of a franchise requirement based on income would further delay the enfranchisement of women since they are poorer than men. Therefore, we should expect the general level of democracy to facilitate the decision to enfranchise women.

The results we have reached so far also shed light on the implication of women's franchise for the size of government. Its expansion following women enfranchisement is to be expected only in societies where the cost of disenfranchisement is high relative to women's relative wage and public 
good preferences, i.e., those factors that imply a large differential between the political choice of men vs. women. Namely, in culturally conservative societies where such cost is low, it is legitimate to expect that enfranchisement occurs only when the wage gap is significantly reduced and/or when the preferences gap is moderate. This implies in turn a limited impact of enfranchisement on the size of government. On the other hand, in progressive societies where the cost is large, suffrage extension might be associated with a significant shift in the median voter's choice and a subsequent large impact on the size of government. Our results can explain the seemingly contradictory historical and comparative evidence regarding the impact of women suffrage on the size of government. This result is summarized in the following proposition.

Proposition 2 For countries with similar levels of the gender-related wage and preferences gaps, the impact of the enfranchisement of women on the size of government increases with the cost of disenfranchisement.

\section{Extensions of the basic model}

\subsection{Endogenous preferences for the public good}

The results we have so far derived depend crucially on a parameter, the preference for public goods, that we have assumed to be exogenous and time invariant. However, it may be hard to disentangle the impact on a woman's choice of her relative wage from that of her preference parameter. To address this concern, we extend the basic formulation to allow for an endogenous process of preference formation linking a higher preference for the public good to a lower income level. Following this intuition, let $\gamma_{t}^{F}=\frac{w_{t}^{M}}{w_{t}^{F}}$ and $\gamma_{t}^{M}=1$. Equation (9) is modified as follows:

$$
\tau_{t}^{*}=1-\frac{y_{t}^{*} / \gamma_{t}^{*}}{y_{t}}
$$

where the median value of the preference parameter, $\gamma_{t}^{*}=\frac{1}{2}+\frac{1}{2} \frac{w_{t}^{M}}{w_{t}^{F}}$, grows over time with the reduction of the wage gap, although it never converges to 1 since physical labor is only endowed to men. It follows that the level of the tax that applies under universal suffrage declines over time and gets closer to the tax that is set under exclusive male suffrage. Therefore, this process accelerates the enfranchisement of women since it magnifies the impact of the development process on relative wages.

Our results in the basic model also rely on a second exogenous parameter, the cost of women's disenfranchisement. However, since our interpretation of such cost is based on a country's culture, 
it is safer in this case to accept its exogeneity. On the other hand, even if culture, and in particular family culture, are strongly associated with slow-varying traits, such as religious affiliation, it cannot be denied that some adaptation does take place. By endogeneizing the cost of disenfranchisement as a decreasing function of, once again, the gender wage gap, we would obtain a cost which is increasing over time, with a consequent acceleration of women's enfranchisement. An increasing cost would be consistent with the historical evidence regarding the gradual strengthening of the movement for women's suffrage.

\subsection{Couples as decision makers}

While in the previous analysis we have modeled men and women as independent decision makers, an established tradition within the literature that distinguishes the roles of men and women has focused on their interaction within the family (see Chiappori, 1988). Doepke and Tertilt (2007) also address the issue of women's rights from an intra-family perspective. In this subsection, we develop an extension of our basic model where men and women interact within a bargaining model of the family. The goal is to show that the main conclusions from the basic model carry over to the present variant.

Assume that all men are matched with all women in a perfectly assortative fashion according to their labor endowments, so that the best-endowed man mates the best-endowed woman, and so on. A couple's utility function is a weighted average of the man's and the woman's utility functions, according to

$$
u_{t}^{h C}=\beta u_{t}^{h M}+(1-\beta) u_{t}^{h M}
$$

for $h=1,2, \ldots, \frac{1}{N}$, where as in (4) utility depends on private consumption and a public good, and the latter is valued by women more than by men. The parameter $\beta$ captures the relative bargaining position of men and women, i.e., the level of women's rights in society. Assume that $\beta$ is set by men, reflecting their larger endowment of labor and economic power. The couple's budget constraint is given by

$$
c_{t}^{h M}+c_{t}^{h F} \leq\left(1-\tau_{t}\right) y_{t}^{h C}
$$

where $y_{t}^{h C}=y_{t}^{h M}+y_{t}^{h F}$ is the couple's income. It is sufficient to impose non-linearity of the utility function in the level of consumption in order to derive an optimal sharing rule for the couples' consumption. It is also straightforward to derive the equilibrium tax rate set by the median couple as 


$$
\tau_{t}^{* C}=1-\frac{y_{t}^{* C} / \gamma^{C}}{y_{t}^{C}}
$$

where $\gamma^{C}=\beta+(1-\beta) \gamma^{F}$. The tax rate is decreasing in $\beta$ : the lower is the bargaining power of women within the family, the lower is public good provision. Thus, as long as women are treated as inferior, the associated tax rate is smaller than in an equal rights society. Men will grant equal rights to women, by setting $\beta=\frac{1}{2}$, only if the cost of accepting a higher tax rate, and a smaller share of the private consumption good, is lower than the cost, $\delta$, carried by women's alienation. To be noticed it that, in this variant of the basic model, the share of the private consumption good also plays a role, while the gender wage gap does not. The latter feature in turn implies that men base their choice of $\beta$ solely on $\gamma^{F}$ and $\delta$, i.e., independently of the stage of the process of development. Only a shock to these parameters could justify a shift in the gender balance of power.

\section{Empirical findings}

\subsection{Data}

We base our empirical investigation on the predictions of the model on a data set covering 22 countries over the 1870-1930 period. For most variables, we construct a five-year panel data set, taking the observation at the beginning of each five-year period. ${ }^{6}$

To test Proposition 1, we select the dependent variable by coding information on women suffrage to construct a dummy for countries that have at least partial women suffrage at the beginning of each five-year period.

The model predicts three main candidates as determinants of the enfranchisement of women: the gender wage gap, the gender gap in public good preferences, and the cost of disenfranchisement.

While data on the gender wage gap are not available for our sample, we show in our model that the gender wage gap is inversely related to the general level of development. This relationship is also documented empirically by Goldin (1990). We therefore proxy for the gender wage gap with the per capita level of GDP in constant dollars (in logarithms). As an alternative measure of development, we also collect data on the agricultural share of labor.

For the gender-based discrepancy in the preferences for the public good we use as a proxy the presence of divorce legislation. We code this variable at the beginning of each five-year period. The idea is that the availability of divorce induces marital insecurity and therefore a higher preference for

\footnotetext{
${ }^{6}$ We prefer this procedure to averaging the five-yearly data, since averaging introduces additional serial correlation.
} 
public goods for women in the face of an uncertain future. This interpretation has been suggested by Lott and Kenny (1999), who link differential preferences toward the size of government in the United States before 1940 to marital instability, and by Edlund and Pande (2001), who trace the post-war evolution of differential political preferences in the same country to family breakdown.

As shown by Algan and Cahuc (2006), the conception of the gender role in society is strongly influenced by religion, with Catholics and Muslims being more prone to support a traditional view if compared to Protestants, Jews and non religious people. It is reasonable to assume that the cost of disenfranchisement is smaller in societies where culture, and in particular family culture, favors a traditional role for women. For our sample, the most important distinction appears to be the one between the Catholic and the other religions, so our proxy for the cost of disenfranchisement is the share of Catholics over population, with a higher share being associated with a lower cost. ${ }^{7}$

We complete our data set with a variable capturing the overall level of democracy. To this aim we select a standard measure of democracy represented by the Polity variable from the Polity IV data set, which includes information on several characteristics of a political system irrespectively, however, of women suffrage. Finally, we also select additional variables which may play an independent role: namely, a measure of education and a dummy reflecting legal origins.

To test Proposition 2, we employ as dependent variable a measure of the size of government over GDP compiled by Lindert (1994) with a focus on social spending. In particular, spending for infrastructure and defense is not included. ${ }^{8}$ Total government expenditures are also decomposed into expenditures for welfare, pensions, health, and housing. All government data are only available at the beginning of each decade, starting in 1880. Therefore, this second part of the empirical investigation is based on a ten-year panel data set. Adapting previously cited specifications conducted over comparable samples, we include among our covariates (the logarithm of) per capita GDP, the agricultural share, a measure of the age structure of the population capturing the weight of the young, the level of democracy, and a measure of the presence of Catholics, in addition to the women suffrage dummy which is the focus of our attention.

Detailed information on each variable and its sources is provided in the Data Appendix. Table 2 reports summary statistics for the variables in our data set.

\footnotetext{
${ }^{7}$ The variables' range is on $[0,1]$.

${ }^{8}$ For several countries in our samples the level of government expenditures is 0 , especially in the initial decades. As described by Lindert (1994), very few governments paid nationwide subsidies for pensions, housing and unemployment in 1880 .
} 


\subsection{Results}

\subsubsection{The determinants of women's enfranchisement}

We apply the intuition coming from theory and we investigate the determinants of women's enfranchisement using an empirical specification which treats women suffrage as a function of per capita income, the presence of a divorce legislation, and the presence of Catholicism as the dominant religion, controlling for the general level democracy. We can now detail our hypotheses regarding the potential role of the above mentioned factors.

The level of per capita income is meant to proxy for the gender wage gap, with a higher income being associated with a smaller wage gap and therefore with a smaller discrepancy between the tax chosen by a male median voter and that chosen by a woman. Therefore, per capita income should exert a positive impact of the decision to enfranchise women.

The availability of divorce, if it proxies for marital insecurity and a larger discrepancy between male and female preferences for public goods, should induce a higher tax rate if women were allowed to vote, and therefore should delay women's enfranchisement. Divorce should therefore enter with a negative coefficient.

The more conservative is family culture, as captured by the presence of Catholicism, the less likely is that women are allowed a political voice. The coefficient of the Catholic share should therefore be negative.

Finally, the general degree of democracy should favor the extension of the franchise.

Table 3 reports our five-year regression results over the 1870-1930 period for the presence of women suffrage. In column (1) we present a first parsimonious specification showing that our three main determinants all enter with a significant coefficient with the expected sign. In column (2) we add the level of democracy, which is highly significant and positive, as expected. In the following robustness checks, we always refer as a benchmark to the latter extended specification. In column (3) we enter the five-year lag of all regressors, in order to alleviate the potential problem of reverse causation between women suffrage and its determinants: all results are confirmed despite the smaller sample. Our results so far are based on OLS linear probability regressions but, in column (4), we show that results from a binary, probit model are broadly similar to those of the linear model, despite the fact that Catholicism loses significance. ${ }^{9}$ The panel dimension of the data set, however, is more easily dealt with in a linear model, so that in column (5) we run an OLS

\footnotetext{
${ }^{9} \mathrm{~A}$ logit specification yields results similar to the probit and is not reported for brevity.
} 
specification with fixed country effects. The resulting $\mathrm{R}^{2}$ is improved but our previous conclusions are confirmed. This suggests that, despite the potential for omitted variable bias, due to the fact that other factors may determine the relationship between women suffrage and the regressors we focus on, correcting for these factors through fixed effects does not affect our results. Finally, in column (6) we show that our results are robust also with respect to the inclusion of time effects.

Table 4 adds new covariates, one-by-one, to the pooled OLS regression in Table 3, column (2). In column (1) we add the agricultural share of labor, which is insignificant. When entered as an alternative to income, the agricultural share displays as expected a negative and significant coefficient. The high correlation between these two regressors explains the insignificance of the latter when jointly entered. The next two covariates both add some explanatory power without altering the previous conclusions. In particular, the effect of education is significantly negative, which is somewhat surprising, even if this could be justified by the fact that education in this historical period tended to be a privilege of men, and thus tended to increase the gender wage gap. The effects of a common law legal origin is also significantly negative, which suggests that, at the margin, these countries were slower in implementing reforms. ${ }^{10}$

Overall, we can conclude that our theory of the determinants of women's enfranchisement, which highlights the role to the gender wage gap, as represented by the income level, the gender difference in public good preferences, as proxied by the way divorce legislation shapes family structure, and the type of society's culture, as captured by the relative weight of religious denominations, is indeed supported by the empirical evidence we provide.

\subsubsection{The impact of women's enfranchisement on government size}

An implication of the main proposition in the model predicts that the impact of women suffrage on the size of government should be larger in societies where the cost of disenfranchisement is high relative to those factors that imply a large differential between the political choice of men vs. women, i.e., the gender gaps in wages and public good preferences.

We test this prediction using an empirical specification which treats the size of government as a function of the standard determinants employed in the literature, with and without women suffrage. The other regressors in our specification are the level of income per capita (in logarithms), the agricultural share, the share of young population, the degree of democracy, and the share of Catholics. For a comparable sample of 21 countries over the same 1880-1930 period, Lindert (1994)

\footnotetext{
${ }^{10}$ Analogous (unreported) results are obtained for probit and panel OLS specifications.
} 
finds a positive effect of women suffrage on social spending. ${ }^{11}$ Qualitatively similar results can be found for Europe in Aidt et al. (2006) and Aidt and Dallal (2008), for samples of 12 countries in 1830-1938 and six countries in 1869-1960, respectively. ${ }^{12}$

The main innovation we introduce within the above described framework is to gauge the relevance of the interaction between the presence of Catholicism and women suffrage, in order to clarify to which extent a conservative culture retards women suffrage at least until a stage at which its impact on government - through the gender gaps in wages and public good preferences - is minimized. In other words, a negative sign for the interaction would indicate that in Catholic countries the impact of women suffrage on government is reduced, if compared with non-Catholic countries. In fact, adding this interaction, the coefficient of women suffrage would solely capture the impact on government size for non-Catholic countries. We therefore expect this coefficient to be larger than in a regression where the interaction is not considered.

Table 5 shows our main results using ten-year, Tobit ${ }^{13}$ regressions. In column (1) we only consider standard determinants, without women suffrage, and find a positive and significant impact for income per capita and democracy, while the coefficients of young population and Catholic share are significantly negative, and agriculture is negative but not significant. The positive influence of income appears to support a luxury-good view of government as exemplified by Wagner's Law. However, since it is well-known that the relationship between government and income can be affected by simultaneity problems, we also run the same regression entering the lagged value of income per capita: the (unreported) results are very similar, even if as expected income loses significance (reduced to the $5 \%$ level) to the advantage of democracy. These results are broadly in line with previous studies.

In column (2) we add women suffrage among the regressors and find a positive impact for it, while the impact of the other regressors is confirmed. To address the potential problem of reverse causation between government size and women suffrage, we enter the lagged value of women suffrage, i.e., women suffrage at the beginning of the previous decade. ${ }^{14}$ In column (3) we show

\footnotetext{
${ }^{11}$ Among the other regressors Lindert (1994) includes the lagged value of per capita GDP and its growth rate, the lagged value of the agricultural share, the proportion of young and old individuals, the share of Catholics and Protestants, a democracy dummy, voter turnout and the frequency of executive turnover.

${ }^{12}$ Aidt et al. (2006) include per capita GDP, the urbanization rate, a measure of the enfranchisement of men, a polity dummy, and the share of old population. Aidt and Dallal (2008) also consider gender-related regressors such as the divorce rate, the share of single women and female labor force participation.

${ }^{13}$ The dependent variable is often 0 and limited to non-negative values.

${ }^{14}$ Regressions with the current value of women suffrage yield comparable results, even though its level of significance
} 
that adding an interaction between women suffrage and the share of Catholics clarifies the channels through which women suffrage affects the size of government. As expected, the coefficient of women suffrage is now larger and strongly significant at $1 \%$. Moreover, the interaction effect is also significant and with the expected negative sign. In more detail, without the interaction, the coefficient of women suffrage - across all countries independently of their religion - is 0.42 . Adding the interaction, the coefficient of women suffrage, which now captures its impact for countries with no Catholics, becomes 0.71. For countries where Catholics represent $100 \%$ of the population, the impact of women suffrage can be computed as the sum of the coefficients of women suffrage and of the interaction, i.e., $0.42-0.71$, which becomes negative at -0.29 . In other words, averaging over the Catholic population, the impact of women suffrage can be computed approximately at a negligible 0.03 .

An analogous set of regressions where divorce is also entered yield nearly identical results, as the coefficient of divorce is always insignificant.

Our women suffrage dummy refers to the year when legislation was passed. However, we also codified an alternative dummy with reference to the time at which women first voted. In practice the two dummies are very highly correlated so that all the above results can be replicated with the alternative dummy definition.

It has been argued that women suffrage might have an impact non only on the size of government, but also on its composition. In Table 6, again for Tobit specifications, we test this hypothesis by regressing our variables on each component of government expenditures. Overall, regression results for individual components are weaker, as it is the case in all previous studies. Nevertheless, we find that indeed the impact of women suffrage differs across components. The pattern established for general expenditures is more closely followed by the pensions, health, and housing components, despite a lower significance level, while welfare expenditures are actually negatively affected by women suffrage, although insignificantly so. These difformities, however, can at least in part be explained by the differential timing of each component's growth. In particular, welfare expenditures, which essentially comprise old-style poor relief, were the first to be expanded during the initial decades of the sample, while other forms of intervention were developed later, and therefore appear to be more closely associated with women suffrage reforms, which also came relatively late in the sample.

The results from Tables 5 and 6 hold qualitatively also under OLS regressions with country is lower. 
fixed effects.

Overall, our results confirm the relevance of women suffrage as a determinant of the size of government and, more importantly, also clarify that the relative strength of this channel depends on the factors that determine women suffrage. If women suffrage is granted because of a large cost of disenfranchisement, as it is the case in countries with a more progressive culture towards women, the discrepancy between the tax rates chosen by a male and a female median voters is such to imply an increase in the size of government, both because women are poorer, and because they display a higher preference for public goods. On the other hand, in Catholic countries with a small cost of disenfranchisement we should expect women suffrage to be granted only when a male and a female median voter would make a similar choice regarding tax rates, with a reduced impact on the size of government.

\section{Conclusion}

We have explored the determinants of women's enfranchisement and found that women are enfranchised sooner under a lower gender wage gap, a lower gender gap in the preferences for public goods, and a higher cost of disenfranchisement. Since the gender wage gap is in turn related to the relative reward of mental vs. physical labor, women's enfranchisement is accelerated by the process of capital accumulation and industrialization. Thus the model establishes a relationship between the level of economic development and women's political status. The driving force of enfranchisement is the fact that economic development makes the women's preferred tax rate closer to that of the men's, which in turn increases the relative cost of disenfranchisement. At the same time, the process is affected by additional factors that reflect the structure of the family and the dominant culture. We have also studied the implications of women's enfranchisement for the size of government, and shown that its expansion following women's enfranchisement is only justified in societies where the cost of disenfranchisement is high relative to the gender wage gap and the gender gap in public good preferences.

We have empirically tested the implications of the model for a sample of 22 countries over the 1870-1930 period. We have proxied the gender wage gap with the level of per capita income. The proxy we have employed for the gender gap in the preferences for public goods is the availability of divorce, which implies marital instability and a more vulnerable social and economic position for women. We have captured the cost of disenfranchisement with a measure of society's culture 
given by religion, where the presence of Catholicism is associated with a more traditional view of women's role, and therefore a smaller cost of disenfranchisement. We have shown that, consistently with the model's predictions, women suffrage is affected positively by the per capita income level, negatively by the presence of Catholicism and the availability of divorce, even after controlling for the general level of democracy. Moreover, our results show that the size of government is positively affected by women suffrage only in societies with a more progressive family culture, as indicated by the negative coefficient of the interaction between women suffrage and the proportion of Catholics.

The main focus of our investigation is the 1870-1930 period, since it includes the unique transitional phase between the males-only franchise and the extension of the franchise to women in those countries that are now modern industrial democracies. Nevertheless, some of the implications of our results can also be usefully applied to a comparative analysis of women's rights across countries with different levels of development. While most countries of the world now practice universal suffrage, the right of women to vote only represents a first stage in the process of full political, economic and social equality.

Further understanding of the causes and consequences of women's rights is in our agenda for future research. 


\section{DATA APPENDIX}

The sample includes 22 countries over the 1870-1930 period. The countries are Argentina, Australia, Austria, Belgium, Brazil, Canada, Denmark, Finland, France, Germany, Greece, Ireland, Italy, the Netherlands, New Zealand, Norway, Portugal, Spain, Sweden, Switzerland, the United Kingdom, and the United States. Data refer to the initial year of each of the 13 five-year periods, except for the data on government over GDP, government components over GDP, and the young share, which are only available at the beginning of each decade starting from 1880. In a few cases data from adjacent years had to be substituted. The following list describes each variable in the data set and indicates its sources.

Women suffrage: Dummy for countries that have at least partial women suffrage. We construct this variable on the basis of information from Flora (1983), Lindert (1994), and a variety of library sources.

Log GDP pc: The logarithm of per capita GDP in 1990 International Geary-Khamis dollars. The source is Maddison (2001).

Divorce: Dummy for countries that allow divorce. We assume that divorce is not allowed if it is restricted to religious minorities (as for example in Austria) or if it is only achievable through an Act of Parliament (as for example in Canada). We construct this variable on the basis of information from Flora (1983) and Phillips (1988).

Catholic share: Catholics over population. Five-year data are adapted from ten-year data in Lindert (1994).

Democracy: Polity variable. The original range on the interval $[-10,10]$ is normalized on $[-1,1]$. The source is Polity IV (2002).

Agricultural share: Work force employed in agriculture over work force. The source is Banks (2001).

Education: Primary and secondary school enrollment over population. The source is Banks (2001).

Common law: Dummy for countries with a common law legal origin. The source is La Porta et al. (1999).

Government/GDP: Total government social transfers over GDP. The source is Lindert (1994).

Young share: Population aged 20 to 39 over total population. The source is Lindert (1994). 
Welfare expenditures/GDP: Government expenditures for welfare over GDP. The source is Lindert (1994).

Pensions expenditures/GDP: Government expenditures for pensions over GDP. The source is Lindert (1994).

Health expenditures/GDP: Government expenditures for health over GDP. The source is Lin$\operatorname{dert}(1994)$.

Housing expenditures/GDP: Government expenditures for housing over GDP. The source is Lindert (1994). 


\section{REFERENCES}

Abrams, B.A. and Settle, R.F., 1999, Women's Suffrage and the Growth of the Welfare State, Public Choice 100, 289-300.

Acemoglu, D. and Robinson, J., 2000, Why Did the West Extend the Franchise? Democracy, Inequality and Growth in Historical Perspective, Quarterly Journal of Economics 115, 1167-99.

Aidt, T.S. and Dallal B. 2008, Female Voting Power: The Contribution of Women's Suffrage to the Growth of Social Spending in Western Europe (1869-1960), Public Choice 134, 391-417.

Aidt, T.S., Dutta, J. and Loukoianovac, E., 2006, Democracy Comes to Europe: Franchise Extension and Fiscal Outcomes, European Economic Review 50, 249-83.

Alesina, A. and Ichino, A., 2007, Gender Based Taxation, mimeo.

Algan, Y. and Cahuc, P., 2006, Job Protection: The Macho Hypothesis, Oxford Review of Economic Policy 22, 290-410.

Banks, A., 2001, Cross-National Time Series, 1815-1999, Center for Comparative Political Research, State University of New York, Binghamton.

Bertocchi, G., 2006, The Law of Primogeniture and the Transition from Landed Aristocracy to Industrial Democracy, Journal of Economic Growth 11, 41-68.

Bertocchi, G. and Spagat, M., 2001, The Politics of Co-optation, Journal of Comparative Economics 29, 591-607.

Bisin, A. and Verdier, T., 2000, Beyond the Melting Pot: Cultural Transmission, Marriage, and the Evolution of Ethnic and Religious Traits, Quarterly Journal of Economics 115, 955-88.

Bolton, P. and Roland G., 1996, Distributional Conflicts, Factor Mobility, and Political Integration, American Economic Review 86, 99-104.

Botticini, M. and Eckstein, Z., 2005, Jewish Occupational Selection: Education, Restrictions, or Minorities?, Journal of Economic History 65, 922-48.

Cavalcanti, T. and Tavares, J., 2006, Women Prefer Larger Government: Growth, Structural Transformation and Government Size, CEPR Discussion Paper No. 5667.

Chattopadhyay, R. and Duflo, E., 2004, Women as Policy Makers: Evidence From a Randomized Experiment in India, Econometrica 72, 1409-43.

Chiappori, P.A., 1988, Rational Household Labour Supply, Econometrica 56, 63-89.

Cipriani, M., Giuliano, P. and Jeanne, O., 2007, Like Mother Like Son? Experimental Evidence on the Transmission of Values from Parents to Children, IZA Discussion Paper No. 2768. 
Costa, D., 2000, From Mill Town to Board Room: The Rise of Women's Paid Labor, Journal of Economic Perspectives 14, 101-122.

Doepke, M. and Tertilt, M., 2007, Women's Liberation: What's in It for Men?, mimeo.

DuBois, Ellen C., 1998, Woman Suffrage and Women's Rights, New York University Press, New York.

Edlund, L. and Pande, R., 2002, Why Have Women Become More Left-Wing? The Political Gender Gap and the Decline in Marriage, Quarterly Journal of Economics 117, 917-61.

Fernandez, R. and Fogli, A., 2007, Culture: An Empirical Investigation of Beliefs, Work, and Fertility, mimeo.

Fleck, E.H., 1993, Woman's Suffrage, Encyclopedia Americana, Grolier, Danbury.

Flexner, E. and Fitzpatrick, E. (eds.), 1996, Century of Struggle: The Woman's Rights Movement in the United States, Harvard University Press, Cambridge.

Flora, P., 1983, State, Economy, and Society in Western Europe 1815-1975: A Data Handbook, St. James Press, Chicago.

Friedberg, L., 1998, Did Unilateral Divorce Raise Divorce Rates? Evidence From Panel Data, American Economic Review 83, 608-27.

Funk, P. and Gathmann, C., 2005, What Women Want: Suffrage, Female Voter Preferences and the Scope of Government, mimeo.

Galor, O. and Moav, O., 2002, Natural Selection and the Origin of Economic Growth, Quarterly Journal of Economics 117, 1133-91.

Galor, O. and Weil, D.N., 1996, The Gender Gap, Fertility, and Growth, American Economic Review 86, 274-387.

Geddes, R. and Lueck. D., 2002, The Gains from Self-Ownership and the Expansion of Women's Rights, American Economic Review 92, 1079-92.

Giuliano, P., 2007, Living Arrangements in Western Europe: Does Cultural Origin Matter?, Journal of the European Economic Association 5, 927-52.

Goldin, C., 1990, Understanding the Gender Gap: An Economic History of American Women, Oxford University Press, New York.

Guiso, L., Sapienza, P. and Zingales, L., 2006, Does Culture Affect Economic Outcomes?, Journal of Economic Perspectives 20, 23-48.

Guiso, L., Sapienza, P. and Zingales, L., 2003, People's Opium? Religion and Economic Attitudes, Journal of Monetary Economics 50, 225-82. 
Hausmann, R., Tyson, L.D. and Zahidi, S., 2007, The Global Gender Gap Report 2007, World Economic Forum, Geneva.

Justman, M. and Gradstein, M., 1999, The Industrial Revolution, Political Transition, and the Subsequent Decline in Inequality in 19-th Century Britain, Explorations in Economic History 36, $109-27$.

Krogstrup, S. and Walti, S., 2006, Women and Budget Deficits, mimeo.

La Porta, R., Lopez-de-Silanes, F., Shleifer, A. and Vishny, R.W., 1999, The Quality of Government, Journal of Law, Economics and Organization 15, 222-279.

Lindert, P., 1994, The Rise in Social Spending 1880-1930, Explorations in Economic History $31,1-37$.

Lizzeri, A. and Persico, N., 2004, Why Did the Elites Extend the Suffrage? Democracy and the Scope of Government, with an Application to Britain's 'Age of Reform', Quarterly Journal of Economics 119, 707-65.

Llavador, H. and Oxoby, R.J., 2005, Partisan Competition, Growth and the Franchise, Quarterly Journal of Economics 120, 1155-89.

Lott, J.R. and Kenny, L.W., 1999, Did Women's Suffrage Change the Size and Scope of Government?, Journal of Political Economy 107, 1163-98.

Maddison, A., 2001, The World Economy: A Millennial Perspective, OECD, Paris.

Meltzer, A.H. and Richard, S.F., 1981, A Rational Theory of the Size of Government, Journal of Political Economy 89, 914-27.

Oswald, A.J. and Powdthavee, N., 2006, Daughters and Left-Wing Voting, IZA Discussion Paper No. 2103.

Owen, A.L. and You, R., 2005, Is Growth Good for Women?, mimeo.

Phillips, R., 1988, Putting Asunder: A History of Divorce in Western Society, Cambridge University Press, Cambridge.

Polity IV, 2002, Political Regime Characteristics and Transitions, 1800-2002, Center for International Development and Conflict Management, University of Maryland.

Stevenson, B. and Wolfers, J., 2007, Marriage and Divorce: Changes and Their Driving Forces, CEPR Discussion Paper No. 6144.

Tabellini, G., 2005, Culture and Institutions: Economic Development in the Regions of Europe, CESifo Working Paper No. 1492.

Washington, E., 2006, Socialization: How Daughters Affect Their Legislator Fathers' Voting on 
Women's Issues, NBER Working Paper No. 11924. 
Table 1

The timing of women suffrage and divorce legislation

\begin{tabular}{|l|c|c|}
\hline \multicolumn{1}{|c|}{ Country } & Women suffrage & Divorce \\
\hline NEW ZEALAND & 1893 & 1867 \\
\hline AUSTRALIA & 1902 & Pre-1860 \\
\hline FINLAND & 1906 & Pre-1860 \\
\hline NORWAY & 1913 & Pre-1860 \\
\hline DENMARK & 1915 & Pre-1860 \\
\hline CANADA & 1917 & 1968 \\
\hline AUSTRIA & 1918 & 1938 \\
\hline GERMANY & 1918 & 1875 \\
\hline IRELAND & $1918)$ & 1996 \\
\hline UK & 1918 & 1857 \\
\hline BELGIUM & 1919 & 1807 \\
\hline NETHERLANDS & 1919 & Pre-1860 \\
\hline SWEDEN & 1919 & Pre-1860 \\
\hline US & 1920 & Pre-1860 \\
\hline PORTUGAL & 1931 & $1910-1940,1977$ \\
\hline SPAIN & 1931 & $1932-391981$ \\
\hline BRAZIL & 1934 & 1975 \\
\hline FRANCE & 1944 & $(1792-1816) 1884$ \\
\hline ITALY & 1945 & 1970 \\
\hline ARGENTINA & 1947 & 1954 \\
\hline GREECE & 1952 & Pre-1860 \\
\hline SWITZERLAND & 1971 & Pre-1860 \\
\hline
\end{tabular}

Table 2

Summary statistics

\begin{tabular}{|l|c|c|c|c|c|}
\hline \multicolumn{1}{|c|}{ Variable } & Observations & Mean & Standard Dev. & Minimun & Maximum \\
\hline Women suffrage & 286 & 0.19 & 0.39 & 0 & 1 \\
\hline Log GDP pc & 266 & 3.41 & 0.22 & 2.83 & 3.80 \\
\hline Divorce & 286 & 0.64 & 0.48 & 0 & 1 \\
\hline Catholic share & 260 & 0.52 & 0.42 & 0.00 & 1.00 \\
\hline Democracy & 247 & 0.39 & 0.60 & -0.9 & 1 \\
\hline Agricultural share & 204 & 0.40 & 0.16 & 0.06 & 0.71 \\
\hline Education & 228 & 0.13 & 0.05 & 0.01 & 0.23 \\
\hline Common law & 286 & 0.27 & 0.44 & 0 & 1 \\
\hline Government/GDP & 114 & 0.60 & 0.76 & 0.00 & 3.4 \\
\hline Young share & 114 & 0.53 & 0.05 & 0.43 & 0.67 \\
\hline Welfare exp./GDP & 114 & 0.28 & 0.36 & 0.00 & 1.69 \\
\hline Pensions exp./GDP & 114 & 0.14 & 0.28 & 0.00 & 1.41 \\
\hline Health exp./GDP & 114 & 0.18 & 0.27 & 0.00 & 1.28 \\
\hline Housing exp./GDP & 114 & 0.01 & 0.05 & 0.00 & 0.37 \\
\hline
\end{tabular}


Table 3

The determinants of women's enfranchisement

\begin{tabular}{|c|c|c|c|c|c|c|}
\hline \multicolumn{7}{|c|}{ Dependent variable: Women suffrage } \\
\hline & $\begin{array}{c}(1) \\
\text { Pooled } \\
\text { OLS }\end{array}$ & $\begin{array}{c}\text { (2) } \\
\text { Pooled } \\
\text { OLS }\end{array}$ & $\begin{array}{c}(3) \\
\text { Pooled } \\
\text { OLS }^{\#}\end{array}$ & $\begin{array}{c}(4) \\
\text { Probit }\end{array}$ & $\begin{array}{c}(5) \\
\text { Fixed } \\
\text { effects } \\
\text { OLS }\end{array}$ & $\begin{array}{c}(6) \\
\text { Time } \\
\text { effects } \\
\text { OLS }\end{array}$ \\
\hline \multirow[t]{2}{*}{ Log GDP pc } & 0.81 & 0.47 & 0.50 & 3.09 & 1.34 & 0.21 \\
\hline & {$[0.11]^{* * *}$} & {$[0.14]^{* * *}$} & {$[0.15]^{* * *}$} & {$[1.03]^{* *}$} & {$[0.19]^{* * *}$} & {$[0.12]^{*}$} \\
\hline \multirow[t]{2}{*}{ Divorce } & -0.13 & -0.20 & -0.19 & -0.90 & -0.39 & -0.15 \\
\hline & {$[0.07]^{*}$} & {$[0.07]^{* *}$} & {$[0.08]^{*}$} & {$[0.42]^{*}$} & {$[0.14]^{* *}$} & {$[0.06]^{*}$} \\
\hline \multirow[t]{2}{*}{ Catholic share } & -0.24 & -0.25 & -0.27 & -0.28 & -5.38 & -0.27 \\
\hline & {$[0.08]^{* *}$} & {$[0.08]^{* *}$} & {$[0.08]^{* *}$} & {$[0.55]$} & {$[1.71]^{* *}$} & {$[0.06]^{* * *}$} \\
\hline \multirow[t]{2}{*}{ Democracy } & & 0.29 & 0.28 & 5.91 & 0.40 & 0.20 \\
\hline & & {$[0.05]^{* * *}$} & {$[0.05]^{* * *}$} & {$[1.65]^{* * *}$} & {$[0.05]^{* * *}$} & {$[0.04]^{* * *}$} \\
\hline Adjusted $\mathrm{R}^{2}$ & 0.22 & 0.35 & 0.34 & & 0.63 & 0.56 \\
\hline McFadden $\mathrm{R}^{2}$ & & & & 0.54 & & \\
\hline Observations & 240 & 212 & 195 & 212 & 212 & 212 \\
\hline
\end{tabular}

Five-year panel. Standard errors in brackets. ${ }^{\#}$ All regressors are lagged five years. * significant at $10 \%,{ }^{* *}$ significant at $5 \%, * * *$ significant at $1 \%$.

\section{Table 4 \\ The determinants of women's enfranchisement:} Additional covariates

\begin{tabular}{|l|c|c|c|}
\hline \multicolumn{4}{|c|}{ Dependent variable: Women suffrage } \\
\hline & $(1)$ & $(2)$ & $(3)$ \\
\hline Log GDP pc & 1.03 & 0.93 & 0.60 \\
\hline & {$[0.28]^{* * *}$} & {$[0.18]^{* * *}$} & {$[0.14]^{* * *}$} \\
\hline Divorce & -0.19 & -0.29 & -0.28 \\
\hline & {$[0.08]^{*}$} & {$[0.08]^{* * *}$} & {$[0.07]^{* * *}$} \\
\hline Catholic share & -0.28 & -0.44 & -0.34 \\
\hline & {$[0.08]^{* * *}$} & {$[0.09]^{* * *}$} & {$[0.08]^{* * *}$} \\
\hline Democracy & 0.30 & 0.33 & 0.35 \\
\hline & {$[0.06]^{* * *}$} & {$[0.05]^{* * *}$} & {$[0.05]^{* * *}$} \\
\hline Agricultural share & 0.39 & & \\
\hline & 0.31 & & \\
\hline Education & & -3.16 & \\
\hline & & $-0.85^{* * *}$ & \\
\hline Common law & & & -0.20 \\
\hline & & & {$[0.07]^{* *}$} \\
\hline Adjusted R & & 0.40 & 0.38 \\
\hline Observations & 0.39 & 182 & 212 \\
\hline
\end{tabular}

Pooled OLS estimates. Five-year panel. Standard errors in brackets. ${ }^{*}$ significant at $10 \%,{ }^{* *}$ significant at $5 \%,{ }^{* * *}$ significant at $1 \%$. 
Table 5

The impact of women's enfranchisement on government size

\begin{tabular}{|l|c|c|c|}
\hline \multicolumn{4}{|c|}{ Dependent variable: Government/GDP } \\
\hline & $(1)$ & $(2)$ & $(3)$ \\
\hline Log GDP pc & 2.66 & 1.87 & 1.67 \\
\hline Agricultural share & {$[0.65]^{* * *}$} & {$[0.67]^{* *}$} & {$[0.64]^{* *}$} \\
\hline & -0.27 & -0.60 & -0.91 \\
\hline Young share & {$[0.65]$} & {$[0.62]$} & {$[0.61]$} \\
\hline & -12.09 & -10.58 & -10.40 \\
\hline Democracy & {$[1.70]^{* * *}$} & {$[1.69]^{* * *}$} & {$[1.61]^{* * *}$} \\
\hline & 0.28 & 0.21 & 0.18 \\
\hline Catholic share & {$[0.13]^{*}$} & {$[0.12]^{*}$} & {$[0.12]$} \\
\hline & -1.45 & -1.32 & -1.17 \\
\hline Women suffrage & {$[0.16]^{* * *}$} & {$[0.16]^{* * *}$} & {$[0.17]^{* * *}$} \\
\hline & & 0.42 & 0.71 \\
\hline Women suffrage.* Cath.share & & {$[0.17]^{*}$} & {$[0.21]^{* * *}$} \\
\hline & & & -0.91 \\
\hline Adjusted R & & & {$[0.42]^{*}$} \\
\hline Observations & 0.73 & 0.75 & 0.77 \\
\hline
\end{tabular}

Tobit estimates. Ten-year panel. The variable Women suffrage is lagged ten years. Standard errors in brackets. * significant at $10 \%$, ** significant at $5 \%$, $* * *$ significant at $1 \%$.

\section{Table 6}

The impact of women's enfranchisement on government components

\begin{tabular}{|l|c|c|c|c|}
\hline \multicolumn{5}{|c|}{ Dependent variables: } \\
\hline & $\begin{array}{c}\text { Welfare } \\
\text { expenditures/ } \\
\text { GDP }\end{array}$ & $\begin{array}{c}\text { Pensions } \\
\text { expenditures/ } \\
\text { GDP }\end{array}$ & $\begin{array}{c}\text { Health } \\
\text { expenditures/ } \\
\text { GDP }\end{array}$ & $\begin{array}{c}\text { Housing } \\
\text { expenditures/ } \\
\text { GDP }\end{array}$ \\
\hline & $(1)$ & $(2)$ & $(3)$ & $(4)$ \\
\hline Log GDP pc & 0.10 & 0.88 & 0.97 & 1.30 \\
\hline Agricultural share & {$[0.40]$} & {$[0.52]^{*}$} & {$[0.33]^{* *}$} & {$[0.57]^{*}$} \\
\hline & -0.85 & -0.31 & -0.06 & -0.55 \\
\hline Young share & {$[0.39]^{*}$} & {$[0.50]$} & {$[0.31]$} & {$[0.30]^{*}$} \\
\hline & -5.17 & -5.04 & -3.58 & -2.71 \\
\hline Democracy & {$[1.02]^{* * *}$} & {$[1.39]^{* * *}$} & {$[0.81]^{* * *}$} & {$[0.95]^{* *}$} \\
\hline & 0.00 & 0.23 & 0.16 & -0.15 \\
\hline Catholic share & {$[0.08]$} & {$[0.11]^{*}$} & {$[0.07]^{*}$} & {$[0.07]^{*}$} \\
\hline & -0.75 & -0.38 & -0.38 & -0.01 \\
\hline Women suffrage & {$[0.11]^{* * *}$} & {$[0.14]^{* *}$} & {$[0.09]^{* * *}$} & {$[0.11]$} \\
\hline & -0.01 & 0.32 & 0.24 & 0.10 \\
\hline Women.s. ${ }^{*}$ Cath.sh. & {$[0.13]$} & {$[0.16]^{*}$} & {$[0.10]^{*}$} & {$[0.10]$} \\
\hline & 0.12 & -0.08 & -0.74 & -0.55 \\
\hline Adjusted R ${ }^{2}$ & {$[0.27]$} & {$[0.31]$} & {$[0.24]^{* *}$} & {$[0.32]^{*}$} \\
\hline Observations & 0.56 & 0.54 & 0.64 & 0.58 \\
\hline
\end{tabular}

Tobit estimates. Ten-year panel. The variable Women suffrage is lagged ten years. Standard errors in brackets. * significant at 10\%, ${ }^{* *}$ significant at $5 \%,{ }^{* * *}$ significant at $1 \%$. 